\title{
Tribute to Muriel Topaz
}

A woman of many accomplishments, Muriel Topaz was a professional notator, writer, educator, editor, and stager. She was Director of Labanotation at the Dance Notation Bureau from 1970 to 1978 , continuing as Executive Director from 1978 to 1985 , and left the Bureau for the only job that would have tempted her to leave, Director of the Dance Division at The Juilliard School, where she served until 1992. In 1998 she was named a John Simon Guggenheim Foundation Fellow, allowing her to do research for her book Undimmed Lustre: The Life of Antony Tudor (2002). She was Editor-in-Chief for Choreography and Dance Studies from 1993 to 1999 and notated works by Balanchine, Tudor, Taylor, Limón, and Humphrey, among others. The last project she worked on was researching, reconstructing, and staging Tudor's The Planets, a ballet choreographed in 1933 and not performed since the 1940 .

All of us in the notation community admired her vision. She worked tirelessly to bring the importance of documenting our art form to the attention of the dance field; and she never ceased the effort to document as much of the dance of our time as possible. Under her leadership, the Dance Notation Bureau expanded and the number of works that were notated each year increased. She placed the first full-time Labanotator at a professional company, the Paul Taylor Dance Company. During her career she personally produced fifty-two notation scores and trained many of the notators in the next generation, passing along her careful and thorough approach. She notated classroom exercises with the same care she gave to the notation of a masterwork.

Mickey, as she was affectionately known, gave her all to everything she did. When she was the Executive Director of the DNB, she was most often the last one to leave at night. We went out the door and she was still there working. She encouraged others to reach out and try new things and supported staff members in wanting to grow. When we did well, she expressed her pride. I admired and learned from her.

I would like to speak of Mickey's future, because she will continue to be with us.

- Every time any of the many works she notated or arranged to have notated are performed, a part of her will be on stage. Because of Mickey's talents, vision, and persuasiveness these works have been scored and our children, our children's children, and their children will continue to enjoy these works of art.

- Every time Antony Tudor's The Planets is staged, Mickey will be in rehearsal. Not 


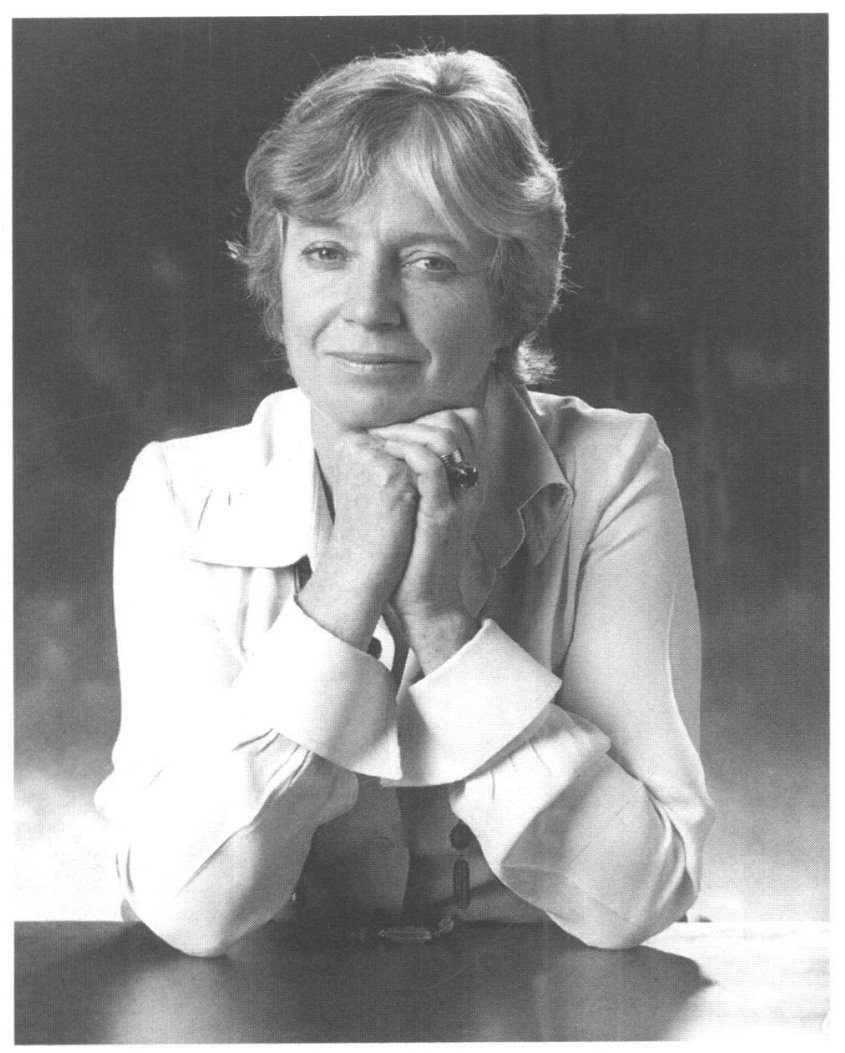

Courtesy of Dance Notation Bureau.

only was she part of the team that reconstructed it, but also her notation score ensures that what was reborn will not be lost again.

- Every time a student opens Mickey's book Elementary Labanotation: A Study Guide, and becomes excited about what Labanotation can do for a dancer, Mickey will be with us.

- Every time one of the students who came through Juilliard during her years there creates a new work, inspires a student, performs on stage, her influence will be there.

- Every time I arrange for the notation of a new score, she will be looking over my shoulder with approval. Her mentoring, example, friendship, and belief in me have helped me to become who I am today.

Mickey will live on in each of us whom she taught, mentored, and loved. We will take with us and pass on to the next generation, not only the knowledge she imparted, but also her way of caring for the next generation, taking joy in their successes, and feeling happiness and fulfillment when they reach new heights of accomplishment. 